\title{
Standardization of ${ }^{68} \mathrm{Ge} /{ }^{68} \mathrm{Ga}$ Using Three Liquid Scintillation Counting Based Methods
}

\section{B. E. Zimmerman, J. T. Cessna, and R. Fitzgerald}

Ionization Radiation Division, National Institute of Standards and Technology, Gaithersburg, MD 20899

bez@nist.gov jeffrey.cessna@nist.gov ryan.fitzgerald@nist.gov
A solution containing ${ }^{68} \mathrm{Ge}$ in equilibrium with its daughter, ${ }^{68} \mathrm{Ga}$, has been standardized for the first time at the National Institute of Standards and Technology (NIST) using 3 liquid scintillation-based techniques: live-timed $4 \pi \beta-\gamma$ anticoincidence (LTAC) counting, the Triple-to-Double Coincidence Ratio (TDCR) method, and ${ }^{3} \mathrm{H}$-standard efficiency tracing with the CIEMAT $/$ NIST (CNET) method. The LTAC technique is much less dependent on level scheme data and model-dependent parameters and was thus able to provide a reference activity concentration value for the master solution with a combined standard uncertainty of about $0.3 \%$. The other two methods gave activity concentration values with respective differences from the reference value of $+1.2 \%$ and $-1.5 \%$, which were still within the experimental uncertainties.
Measurements made on the NIST " $4 \pi$ " $\gamma$ secondary standard ionization chamber allowed for the determination of calibration factors for that instrument, allowing future calibrations to be made for ${ }^{68} \mathrm{Ge} /{ }^{68} \mathrm{Ga}$ without the need for a primary measurement. The ability to produce standardized solutions of ${ }^{68} \mathrm{Ge}$ presents opportunities for the development of a number of NISTtraceable calibration sources with very low $(<1 \%)$ relative standard uncertainties that can be used in diagnostic medical imaging.

Key words: anticoincidence counting; CIEMAT/NIST method; germanium-68; liquid scintillation counting; positron emitter; standardization; TDCR method.

Accepted: September 10, 2008

Available online: http://www.nist.gov/jres

\section{Introduction}

The use of Positron Emission Tomography (PET) as a tool for diagnosing diseases, particularly cancer, continues to rise at a rate of about $20 \%$ per year [1], partially due to technological advances that allow for more quantitative data to be collected. The ability to consistently acquire truly quantitative imaging data depends on the use of radioactivity standards traceable to the National Institute of Standards and Technology (NIST).

Currently the most widely used radionuclide in PET imaging is ${ }^{18} \mathrm{~F}$. Although NIST has previously

\footnotetext{
${ }^{1}$ CIEMAT is an acronym for Centro de Investigaciones Energéticas, Medioambientales y Tecnológicas, which is the National Metrology Institute of Spain.
}

standardized ${ }^{18} \mathrm{~F}[2,3]$, its short half-life $(1.83 \mathrm{~h})$ makes it nearly impossible to prepare and distribute Standard Reference Materials to most users. As a potential solution, ${ }^{68} \mathrm{Ge}$, in equilibrium with its daughter, ${ }^{68} \mathrm{Ga}$, has been proposed as a surrogate.

A simplified scheme for the decays of ${ }^{68} \mathrm{Ge}$ and its ${ }^{68} \mathrm{Ga}$ daughter is shown in Fig. 1. Germanium-68 decays by pure electron capture (EC) to the ground state of ${ }^{68} \mathrm{Ga}$ with a half-life of $270.95(16) \mathrm{d}$ [4]. Gallium-68 in turn decays with a half-life of 67.71(9) min by a combination of EC and positron emission primarily to the ground state of ${ }^{68} \mathrm{Zn}$, but also with a branch to an excited state at $1077 \mathrm{keV}$ with a probability of about $3 \%$ and a number of higher excited states with a combined probability of under $0.4 \%$. 


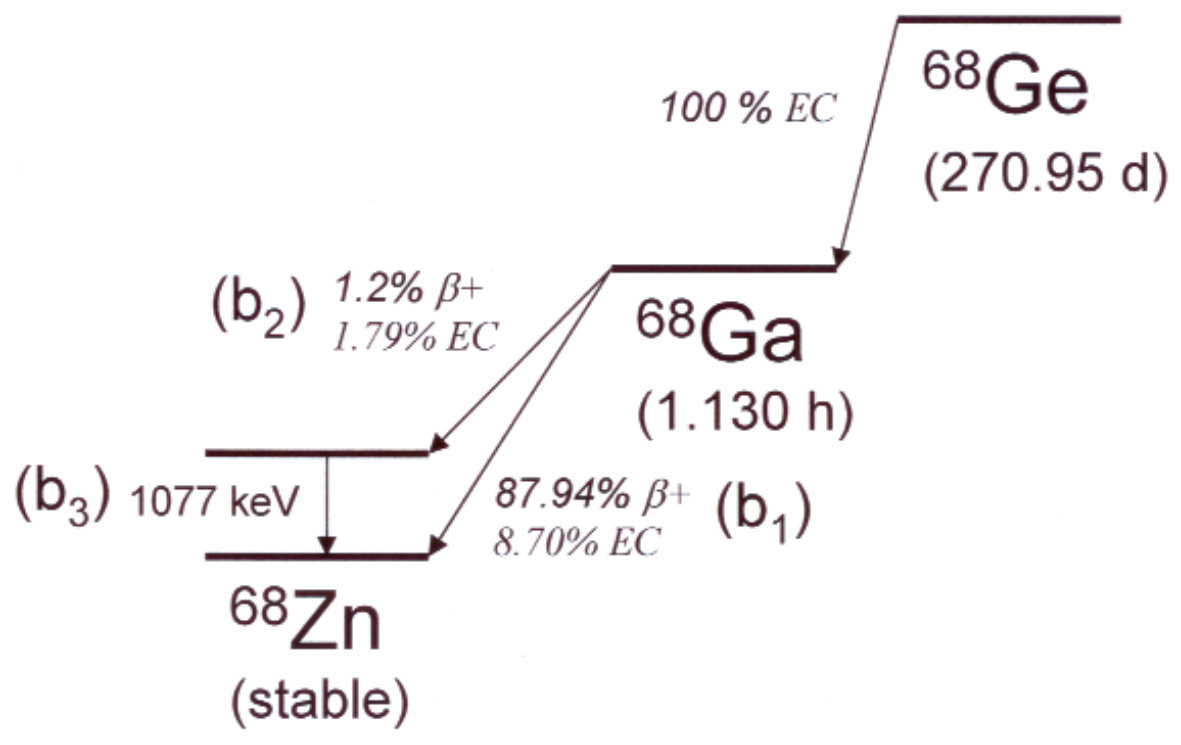

Fig. 1. Simplified decay scheme for ${ }^{68} \mathrm{Ge}-{ }^{68} \mathrm{Ga}$. Data were taken from the DDEP data evaluation [4]. The branching probabilities $\mathrm{b}_{1}, \mathrm{~b}_{2}$, and $\mathrm{b}_{3}$ refer to the two positron emission and gamma emission probabilities, respectively.

The nature of the decay scheme of ${ }^{68} \mathrm{Ge} /{ }^{68} \mathrm{Ga}$ makes it amenable to a variety of different standardization techniques. In 1994, Schönfeld, et al. [5] reported on the results of measurements made with liquid scintillation (LS) counting using the CIEMAT/NIST ${ }^{3} \mathrm{H}$ standard efficiency tracing method (CNET) [6,7], $4 \pi \beta-\gamma$ coincidence, and a calibrated ionization chamber (IC). The data showed good agreement between all three methods, giving activity concentration values within the respective experimental uncertainties (nominally $1 \%$ relative standard uncertainty).

More recently, Grigorescu, et al. [8], reported on the results of measurements using $4 \pi \beta-\gamma$ coincidence counting. As with Schönfeld, et al., the coincidence spectrometer consisted of a proportional counter and $\mathrm{NaI}(\mathrm{Tl})$ detector for the $\beta$ and $\gamma$ detection channels, respectively. Because this experimental arrangement requires the use of dried sources, corrections for the loss of ${ }^{68} \mathrm{Ge}$ due to chemical volatility were necessary in both studies. This effect is reported by Grigorescu to be on the order of $20 \%$ to $26 \%$. Nonetheless, they were able to obtain a measurement result with about a $1 \%$ relative standard uncertainty.

Liquid scintillation (LS) counting has been the method of choice in our laboratory for the measurement of $\beta$-emitting radionuclides, primarily due to the high LS detection efficiency and the relative ease of sample preparation. Methods based on LS counting have another advantage in the context of measuring ${ }^{68} \mathrm{Ge}$ because the sample is introduced into the cocktail while still in solution, thereby eliminating the need to prepare dry sources. Seeking to take advantage of this, we have measured a single solution of ${ }^{68} \mathrm{Ge} /{ }^{68} \mathrm{Ga}$ using three LSbased methods: live-timed $4 \pi \beta-\gamma$ anticoincidence (LTAC) using LS as the $\beta$ counting channel, the Tripleto-Double Coincidence Ratio Method (TDCR) $[9,10]$, and CNET $[6,7]$.

\section{Experimental}

All evaluation of measurement uncertainties throughout this work follow accepted conventions used by the NIST Radioactivity Group and are in accordance with those recommended by the principal metrology organizations [11]. All individual uncertainty components are given as estimated experimental standard deviations (or standard deviations of the mean, if appropriate), or quantities assumed to correspond to standard deviations regardless of the method used to evaluate their magnitude. Unless explicitly stated, all uncertainties cited in this paper are "standard uncertainties," corresponding to one uncertainty interval. One particular exception is the uncertainty reported for the activity concentration of the calibrated ${ }^{68} \mathrm{Ge}$ solution, which is given as an "expanded combined standard uncertainty." In accordance with NIST policy [12], the combined standard uncertainty (calculated by combining the individual uncertainty components in quadrature) is multiplied by a "coverage factor" of $k=2$ to 
obtain an "expanded uncertainty" assumed to give an uncertainty interval having a confidence level of $90 \%$ to $95 \%$.

\subsection{Initial Solution Preparation}

The master solution used in these experiments contained nominally $125 \mathrm{MBq}{ }^{68} \mathrm{Ge}$ in $5 \mathrm{~mL}$ of $0.5 \mathrm{~mol} \cdot \mathrm{L}^{-1} \mathrm{HCl}$ and was prepared by International Isotopes Idaho, Inc. (Idaho Falls, ID) ${ }^{2}$ using ${ }^{68} \mathrm{Ge}$ produced at the $100 \mathrm{MeV}$ Isotope Production Facility at Los Alamos National Laboratory using the ${ }^{\text {nat. }} \mathrm{Ga}(\mathrm{p}, 2 \mathrm{n}){ }^{68} \mathrm{Ge}$ reaction.

A generalized scheme for the preparation of the counting samples is shown in Fig. 2. The first step involved transfer of the master solution out of the shipping vial into a NIST standard $5 \mathrm{~mL}$ flame-sealed ampoule while at the same time performing the first of three serial dilutions that would be needed in order to bring the activity level in one of the ampoules down to that suitable for LS counting. The ampoule used for this study, labeled $A 1$, was prepared by volumetrically adding $1 \mathrm{~mL}$ of the stock solution to an ampoule containing $4 \mathrm{~g}$ of gravimetrically added carrier solution having nominally $45 \mu \mathrm{g}$ each of nonradioactive $\mathrm{Ge}^{+4}$ and $\mathrm{Ga}^{+3}$ per gram of solution using $0.5 \mathrm{~mol} \cdot \mathrm{L}^{-1} \mathrm{HCl}$ as the solvent. The ampoule was weighed again after the addition of the ${ }^{68} \mathrm{Ge}$ to determine the mass of added radioactive solution. Ampoule A2, shown in Fig. 2, was held in reserve for future experiments.

Ampoule $A 1$ was measured in the NIST-maintained radionuclide activity calibrators ("dose calibrators") and the NIST " $4 \pi$ " $\gamma$ IC [13] to allow for the determination of calibration factors in this specific measurement geometry. The solution in $A 1$ was then diluted by a factor of about 200 through two serial gravimetric dilutions, giving two additional ampoules, $A 1 D 1$ and $A 1 D 2$. As an additional check of the dilution factor between $A 1$ and $A 1 D 1$, the latter was also measured in the NIST IC.

\subsection{Liquid Scintillation Source Preparation}

All counting sources for the three counting techniques were prepared using solution $A 1 D 2$. A total of 18 LS cocktails containing ${ }^{68} \mathrm{Ge}$ were prepared for these studies. For the LTAC experiments, $4 \mathrm{~mL}$ of HiSafe-3 (Perkin Elmer, Waltham, MA) or PCS (GE Healthcare

\footnotetext{
${ }^{2}$ Certain commercial equipment, instruments, or materials are identified in this paper to foster understanding. Such identification does not imply recommendation or endorsement by the National Institute of Standards and Technology, nor does it imply that the materials or equipment identified are necessarily the best available for the purpose.
}

Biosciences, Piscataway, NJ) scintillant were added to each of two $3 \mathrm{~cm}$ diameter, glass pseudo-hemispheres. Nominally $0.04 \mathrm{~g}$ of ${ }^{68} \mathrm{Ge}$ solution were gravimetrically added and the hemispheres were sealed using epoxy.

For the TDCR experiments, two cocktails each of HiSafe-3 and PCS were prepared by dispensing $10 \mathrm{~mL}$ of the scintillant into four $22 \mathrm{~mL}$ borosilicate glass LS vials (two per scintillant), followed by the gravimetric addition of nominally $0.04 \mathrm{~g}$ of solution from A1D2. Similarly, 10 cocktails were prepared for the CNET experiments (five vials per scintillant). To vary the counting efficiency of the CNET cocktails, between 2 drops and 18 drops of a 10:1 (by volume) dilution of nitromethane in ethanol were added as a quenching agent to the CNET cocktails in addition to the scintillant and radioactive solution. In order to perform the efficiency tracing, a separate set of 10 LS vials having identical composition to the ${ }^{68} \mathrm{Ge}$ cocktails were prepared using a dilution of a NIST tritiated water Standard Reference Material 4927F [14] in place of the ${ }^{68} \mathrm{Ge}$. In order to make the ${ }^{68} \mathrm{Ge}$ and ${ }^{3} \mathrm{H}$ cocktails as close in composition as possible, nominally $1 \mathrm{~mL}$ of the $\mathrm{Ge}^{4+} / \mathrm{Ga}^{3+}$ carrier was added to each of the cocktails.

Two background blanks (one for each scintillant) were prepared for the TDCR and LTAC measurements in their appropriate vials. In order to properly mimic the composition of the radioactive cocktails, an equivalent mass of nonradioactive carrier solution was added to each blank. For the CNET measurements, four blanks were prepared so as to have the identical sample compositions of the least- and most-quenched of the radioactive ${ }^{68} \mathrm{Ge}$ cocktails. As with the TDCR and LTAC blanks, nonradioactive Ge/Ga carrier was substituted for the ${ }^{68} \mathrm{Ge}$ solution.

\section{$2.34 \pi \beta-\gamma$ Anticoincidence Counting (LTAC)}

The system constructed at NIST uses an LS source optically coupled to an appropriate photomultiplier tube for the beta channel and a thallium-doped sodium iodide $[\mathrm{NaI}(\mathrm{Tl})]$ detector for the $\gamma$-ray channel, as described previously $[15,16]$. The LS-based system is well suited to this case since the source solution does not have to be dried, and therefore, the large (20\% to $26 \%$ ) correction for Ge loss reported by Grigorescu [8] is avoided.

The four active sources were each measured for between 2 and 4 cycles and the blank sources up to 3 cycles during the period from 24 April to 5 May 2007. Each counting cycle consisted of measurements at between 8 to 12 threshold levels on the LS detector for between 200 and 1000 seconds. A minimum of $5 \cdot 10^{6} \mathrm{LS}$ and $1 \cdot 10^{5}$ anti-coincident $\mathrm{NaI}$ detector 


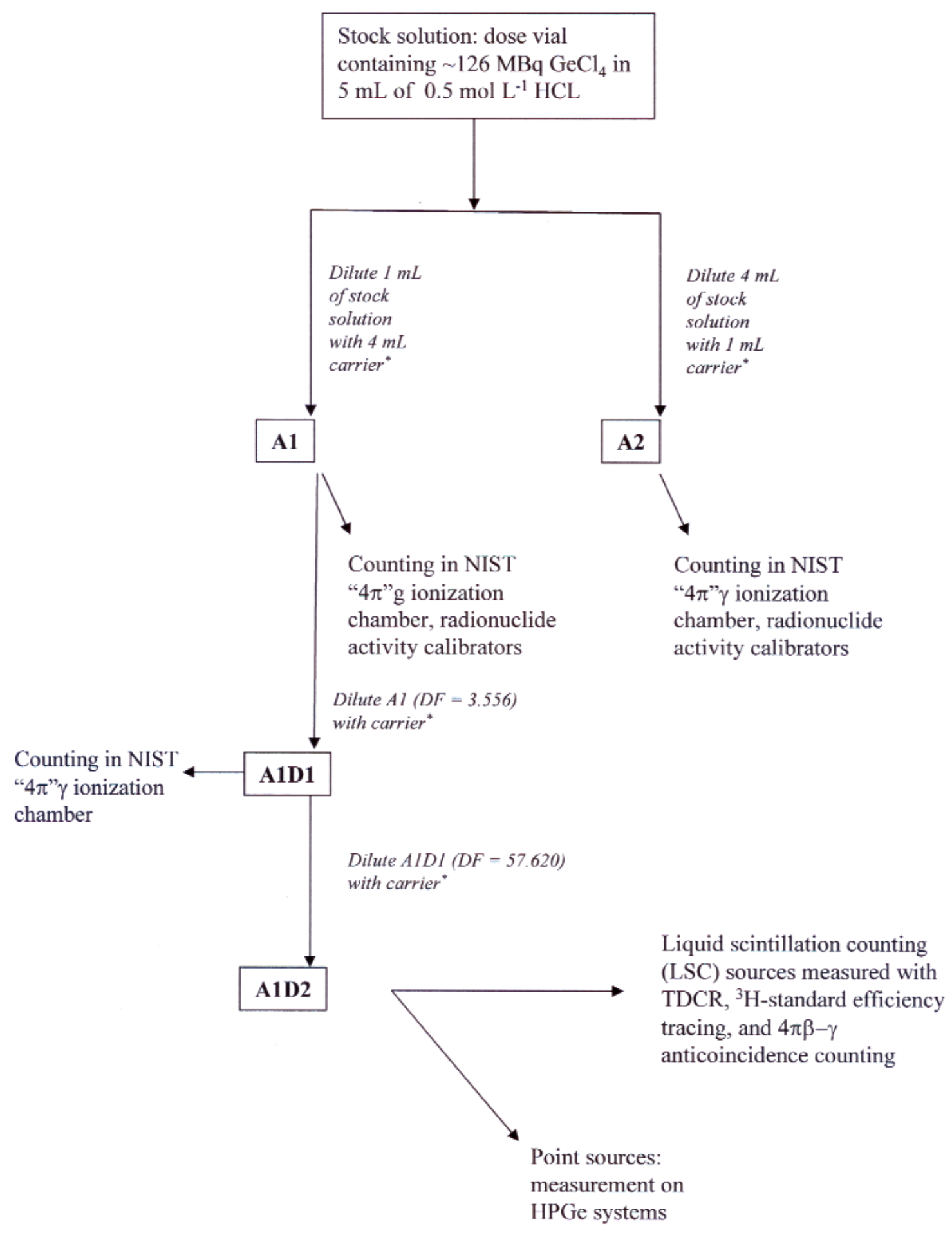

${ }^{*}$ Carrier consisted of nominally $45 \mu \mathrm{g}$ each $\mathrm{Ge}^{+4}$ and $\mathrm{Ga}^{+3}$ in $1 \mathrm{~g}$ solution containing $0.5 \mathrm{~mol} \mathrm{~L}^{-1} \mathrm{HCl}$

Fig. 2. Scheme used for preparation of sources used to calibrate solutions of ${ }^{68} \mathrm{GeCl}_{4}$. 
counts were recorded for each non-blank measurement. The LS signal-to-background ratio for the lowest threshold (highest background) data points was about 950:1, while the signal-to-background ratio for the $\mathrm{NaI}$ detector was about 350:1. Further systematic tests demonstrated that the background variability during the span of the experiment, the variation of extending dead-time, and the presence or absence of the aluminum absorber did not affect the measurement results.

The positron decay of the ${ }^{68} \mathrm{Ga}$ was detected in the LS channel, with count rate $N_{\beta}$, while electron capture events from both ${ }^{68} \mathrm{Ga}$ and ${ }^{68} \mathrm{Ge}$ were avoided by constraining the lower level discriminator (LLD) on the amplified signal to be above about $20 \mathrm{keV}$ beta energy. In this way, the determined activity value was independent of any atomic transitions (all below $11 \mathrm{keV}$ ), and directly proportional to the total positron emission probability. The LS positron efficiency, $\varepsilon_{\beta}$, was varied between about 0.5 and 0.95 using the LLD and extrapolated to 1.0 . The $\mathrm{NaI}(\mathrm{Tl})$ detector was gated on the $511 \mathrm{keV}$ region using a single channel analyzer and the total $\gamma$-ray $\left(N_{\gamma}\right)$ and anticoincidence $\left(N_{A C}\right)$ count rates were recorded. The extrapolation parameter used was $Y \equiv N_{A C} / N_{\gamma} \approx\left(1-\varepsilon_{\beta}\right)$. Most of the $\gamma$-ray counts were due to positron-annihilation decays, detected with efficiency,

$$
\varepsilon_{\text {ann }} \cong \frac{N_{\gamma}}{N_{0}\left(b_{1}+b_{2}\right)}
$$

where $N_{0}$ is the activity and $\left(b_{1}+b_{2}\right)$ is the total positron emission probability. There was an additional, approximately $0.2 \%$, contribution from Compton scattering of $1077 \mathrm{keV} \gamma$-rays, detected with efficiency $\varepsilon_{\gamma 1077}$. Since some of these $1077 \mathrm{keV} \gamma$-rays correspond to electron capture events, and not positron emission, a small $(0.2 \%)$ correction to the intercept was necessary. The modified extrapolation formula is,

$$
N_{\beta}=N_{0}\left(b_{1}+b_{2}\right)(1-Y)\left(\frac{1+\frac{\varepsilon_{\gamma 1077}}{\varepsilon_{\mathrm{ann}}} \frac{b_{3}}{b_{1}+b_{2}}}{1+\frac{\varepsilon_{\gamma 1077}}{\varepsilon_{\mathrm{ann}}} \frac{b_{2}}{b_{1}+b_{2}}}\right),
$$

where the numerator and denominator of the correction term correspond to total $\gamma$-rays and anticoincident $\gamma$-rays, respectively, and the branching probabilities $b_{1}, b_{2}$, and $b_{3}$ are illustrated and enumerated in Fig. 1. Note that the extrapolation is linear in $Y$, and the $Y=0\left(\varepsilon_{\beta}=1\right)$ intercept is given by,

$$
N_{\beta_{\mathrm{int}}} \approx N_{0}\left(b_{1}+b_{2}\right)\left(1+\frac{\varepsilon_{\gamma 1077}}{\varepsilon_{\mathrm{ann}}} \frac{b_{3}-b_{2}}{b_{1}+b_{2}}\right) .
$$

Equation (3) is similar to Eq. (4) in [8], with a significant difference that here we account for the fact that some of the $1077 \mathrm{keV} \gamma$-rays do correspond to a positron branch, and thus do not need to be subtracted. This effect is accommodated by the presence of $b_{2}$ in the numerator of the correction term (final term in Eq. (3)). Corrections due to the LS efficiency for $\gamma$-rays and for coincidences due to those events were not necessary, as described below.

An estimate of $\varepsilon_{\gamma 1077}$ was obtained during a separate set of measurements with a ${ }^{60}$ Co point-source and $\varepsilon_{\text {ann }}$ was estimated using Eq. (1). The correction term was checked by exaggerating the effect during additional measurements made with various $\gamma$-ray energy gates. Gates $G 1, G 2$, and $G 3$ corresponded to a gate around the Compton region of the annihilation spectrum, the annihilation photopeak $(511 \mathrm{keV})$ and the annihilation sum peak $(1022 \mathrm{keV})$ respectively. The sum peak was unresolved from the $1077 \mathrm{keV}$ peak in the $\mathrm{NaI}(\mathrm{Tl})$ detector events. As designed, the data from gates $G 1$ and $G 3$ required large corrections due to reduced $\varepsilon_{\text {ann }}$ and enhanced $\varepsilon_{\gamma 1077}$ respectively. The uncorrected and corrected $N_{0}$ values are shown in Table 1 . The fact that the large corrections for $G 1$ and $G 3$ gave consistent results with $G 2$, supports the use of this method for the small $(0.2 \%)$ correction to the final $N_{0}$ value, based on G2 alone.

Table 1. Calculated ${ }^{68} \mathrm{Ga}$ activity from various $\gamma$-ray gates and using Eq. (3), with and without the final correction term, and relative to the corrected $G 2$ value, (used for the final activity determination). The uncertainties $(k=1)$ on the uncorrected activities are standard deviations of the intercepts from the least-squares fits to the various data sets. The uncertainties $(k=1)$ of the corrected values are from estimates of the uncertainties in $\varepsilon_{\text {ann }}$ and $\varepsilon_{\gamma 1077}$

\begin{tabular}{ccll}
\hline \hline \multicolumn{1}{c}{$\gamma$-ray gate } & Uncorrected $N_{0}(\mathrm{~Bq})$ & Corrected $N_{0}(\mathrm{~Bq})$ \\
\hline$G 1$ - Comptons & $1.020 \pm 0.002$ & $1.002 \pm 0.004$ \\
$G 2$ - photopeak & $1.0021 \pm 0.001$ & $1.0000 \pm 0.0004$ \\
$G 3$ - sum peak & $1.033 \pm 0.002$ & $1.000 \pm 0.007$ \\
\hline
\end{tabular}

No correction in the final result was made for the gamma efficiency of the LS detector, or for coincidences between such events and the $\mathrm{NaI}(\mathrm{Tl})$ detector. For gates $G 1$ and $G 2$, these effects tend to cancel out due to the two-photon annihilation process. If one photon is detected in the LS detector, that efficiency 
can be monitored by the other photon interacting in the $\mathrm{NaI}$ detector [15]. If such an effect were present it would lead to a non-linear efficiency extrapolation. A typical $G 2$ data set and residuals from a linear leastsquares fit are shown in Fig. 3 and it is evident that a linear fit is satisfactory. Yet, a quadratic extrapolation was needed to fit the entire range of $G 3$ (sum peak) data due to the unmonitored LS efficiency for $\gamma$-rays in that configuration. Thus, for $G 3$, a smaller $\varepsilon_{\beta}$ range $(0.9-0.95)$ was employed such that linear and quadratic fits gave consistent results. This value was only used for the $\varepsilon_{\gamma 1077}$ sensitivity test.

Another possible cause for a non-linear extrapolation would be if both the LS and $\mathrm{NaI}(\mathrm{Tl})$ efficiencies differed depending on whether the positron was stopped in the LS hemisphere, or escaped before annihilating. This effect was mitigated by three factors: (1) the fact that most positrons annihilated within the hemisphere, (2) the high LS efficiency, and (3) the well-type geometry of the $\mathrm{NaI}(\mathrm{Tl})$ detector. The sensitivity of the result to this effect was tested by placing an approximately $0.5 \mathrm{~cm}$ thick aluminum foil over the hemisphere and comparing the resulting activity determination. No change in the goodness of the linear fit was detected and the ratio of the intercept with to without the foil was $1.000 \pm 0.001$, where the uncertainty is a standard $(k=1)$ uncertainty on the linear fit coefficients.

\subsection{Liquid Scintillation Counting Using the Triple- to-Double Coincidence Ratio (TDCR) Method}

Each counting source was counted in the NIST TDCR system [17] on at least two separate occasions over the course of 27 days. Counting times were typically $1200 \mathrm{~s}$, which allowed for the accumulation of at least $10^{6}$ counts in each of the three doubles counting channels. For each counting experiment, data were acquired at a minimum of 4 efficiency points, which were varied through the use of a set of grey filters that were fitted over the LS vials. Data were acquired in triplicate at each efficiency point. The experimental efficiencies for the logical sum of double photon coincidence events, $\varepsilon_{\mathrm{LSD}}$, ranged from 0.89 to 1.14 .

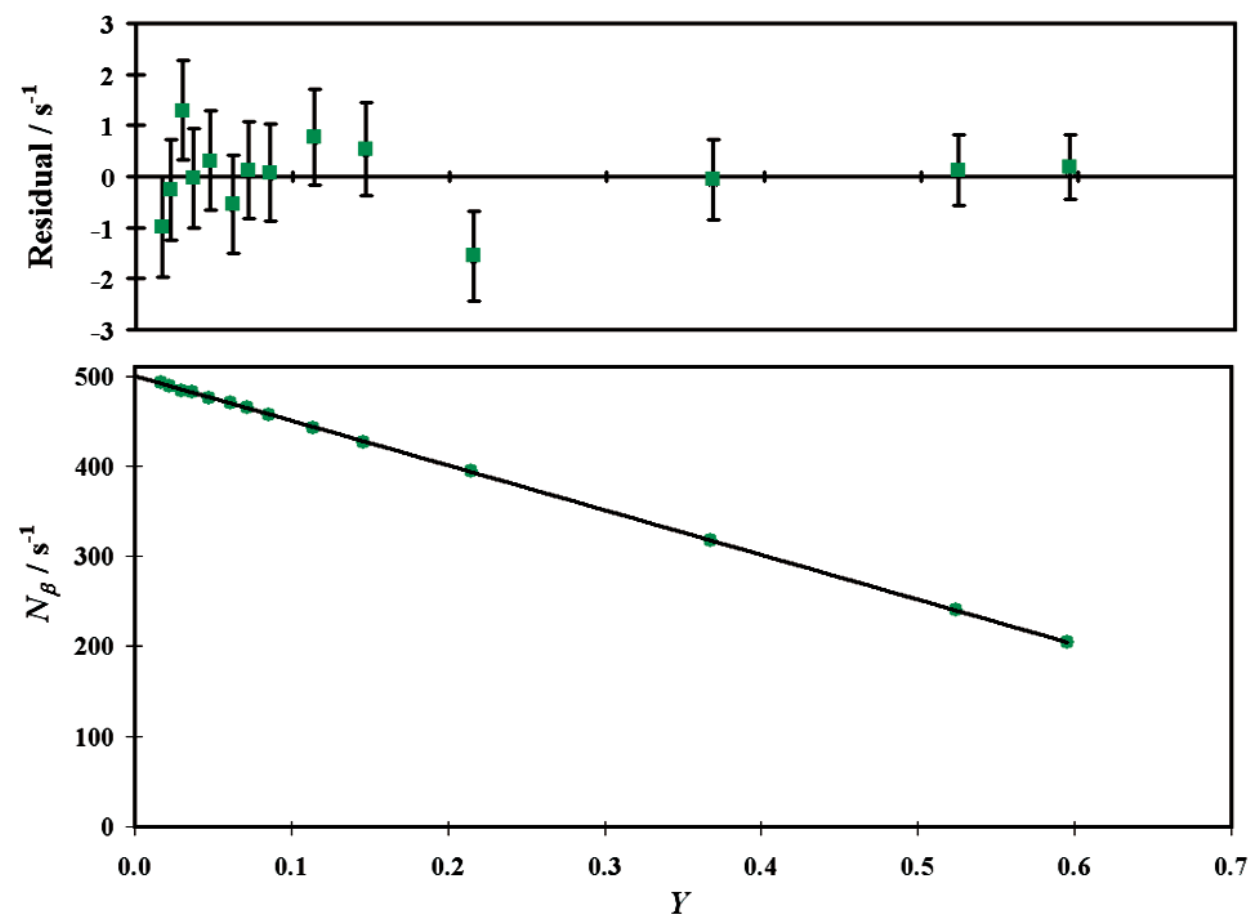

Fig. 3. Typical ${ }^{68} \mathrm{Ga}$ LS rate, $N_{\beta}$, extrapolation versus anticoincidence efficiency, $Y$ (bottom) and residual, $R$, from a linear least-squares fit versus $Y$ (top). Statistical $(k=1)$ uncertainties are shown in the residual plot. 
The counting data were analyzed using a program developed in-house for use with the Mathematica [18] symbolic mathematics package. Details of the program and the computation strategy will be published separately. However, it should be noted that the program calculates the total detection efficiency for the case of decay of ${ }^{68} \mathrm{Ge}$ in equilibrium with its ${ }^{68} \mathrm{Ga}$ daughter. To do this, the program was required to solve the TDCR equations $[9,10,19,20]$ for the EC branch of the ${ }^{68} \mathrm{Ge}$ parent, as well as both the EC and positron decay of the ${ }^{68} \mathrm{Ga}$ daughter. A relatively simplistic model, considering twelve possible decay pathways, was adopted to describe the atomic transitions encountered in the EC decay of ${ }^{68} \mathrm{Ge}$ and ${ }^{68} \mathrm{Ga}$. These are depicted in Fig. 4. The values of the various nuclear and atomic input data were taken from the evaluation of the Decay Data Evaluation Project (DDEP) [4].

The analysis program calculates the individual phototube efficiencies, thereby allowing for correction due to asymmetry in the counting rates in each of thedoubles counting channels. The contribution to the detection efficiency due to detection of the $511 \mathrm{keV}$ anihillation photons was taken into account by using the positron spectrum calculated by the program SPEBETA [21] as input for the Monte Carlo simulation package PENELOPE [22] using the techniques described in [23]. The resulting spectrum of energy (positrons+annihilation photons) absorbed in the LS cocktail was then used as input data for the TDCR analysis code.

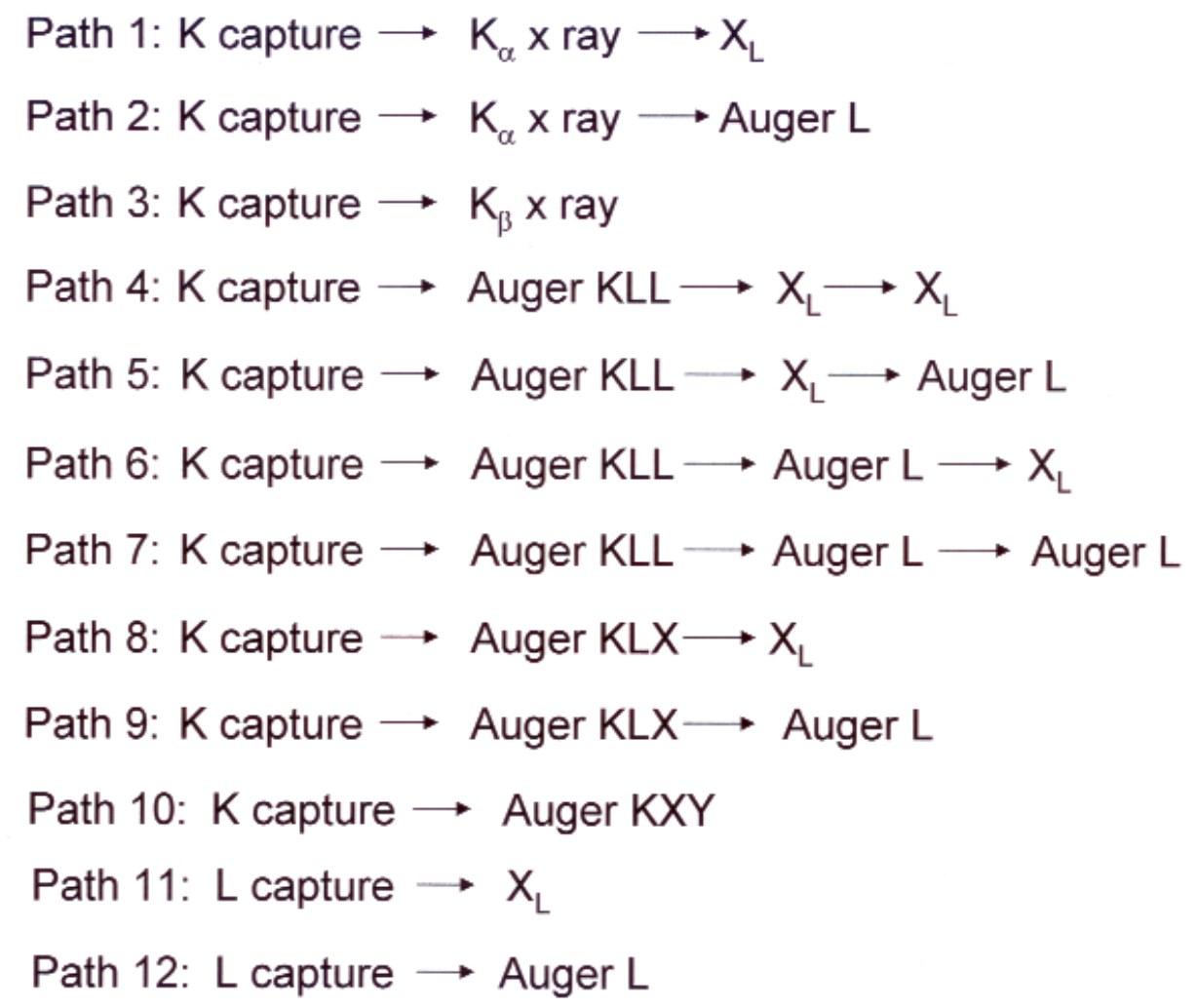

Fig. 4. Energy decay schemes used in calculating TDCR efficiencies for electron capture branches in the decay of ${ }^{68} \mathrm{Ge}$ and ${ }^{68} \mathrm{Ga}$. 
The stopping power, $\mathrm{d} E / \mathrm{d} x$, for electrons in the LS cocktail was calculated by fitting a function of the form

$$
(\mathrm{d} E / \mathrm{d} x)=a+b E+c(\ln E)^{2}+d \ln E / E+e / E
$$

( $E$ is the value of the midpoint energy for each bin of the calculated beta spectrum and $a, b, c, d$, and $e$ are fitting parameters) to data from the NIST ESTAR [24] database using previously published LS cocktail compositions [25].

A separate program, assuming equal phototube efficiencies, was developed for evaluating the effects of varying different input and model parameters. Calculations of $\varepsilon_{\text {LSD }}$ were made as a function of the TDCR for $k B$ values between $0.009 \mathrm{~cm} \cdot \mathrm{MeV}^{-1}$ and $0.018 \mathrm{~cm} \cdot \mathrm{MeV}^{-1}$ and the resulting $\varepsilon_{\mathrm{LSD}}$ values were found to be insensitive to the value of $k B$. For consistency with previous measurements made in this laboratory [26], the value of $k B$ for all analyses was taken to be $0.012 \mathrm{~cm} \cdot \mathrm{MeV}^{-1}$. A plot of the theoretical $\varepsilon_{\mathrm{LSD}}$ values as a function of TDCR at $k B=0.012 \mathrm{~cm} \cdot \mathrm{MeV}^{-1}$ is shown in Fig. 5 .

\subsection{Liquid Scintillation Counting Using the CIEMAT-NIST ${ }^{3} \mathrm{H}-\mathrm{Standard}$ Efficiency Tracing (CNET) Method}

Each LS cocktail was sequentially counted for 10 cycles of $25 \mathrm{~min}$ per source in a Packard (Perkin Elmer, Waltham, MA) 2500TR LS spectrometer. Samples were then removed from the counter, agitated and sequentially counted for 10 cycles of 30 min per source in a Beckman LS6500 (Beckman Coulter, Fullerton, CA) spectrometer.

Efficiency tracing involves calculating a relationship between the measured ${ }^{3} \mathrm{HLS}$ efficiencies and the LS efficiencies expected for ${ }^{68} \mathrm{Ge}$, in equilibrium with its daughter ${ }^{68} \mathrm{Ga}$, over a range of experimental quench indicating parameters [7]. The efficiency tracing computer program CN2004 [27] was used in the analysis of the LS data after changing the default input file to include the nuclear and atomic data found in the DDEP evaluation [4]. The average calculated ${ }^{68} \mathrm{Ge} /{ }^{68} \mathrm{Ga}$ efficiency was nominally $138 \%$ in the Packard LS counter and $147 \%$ in the Wallac LS counter using a $k B$ value of $0.0075 \mathrm{~cm} \cdot \mathrm{Mev}^{-1}$ and assuming that the cocktail had the composition of Ultima Gold as specified in the default CN2004 input files. Plots of the calculated theoretical ${ }^{68} \mathrm{Ge},{ }^{68} \mathrm{Ga}$, and total efficiencies as a function of ${ }^{3} \mathrm{H}$ tritium are given in Fig. 6 .

\subsection{Ionization Chamber Measurements}

For the NIST IC measurements, both $A 1$ and AlD1 were measured 40 times each, in four groups of 10 measurements, alternating with 5 groups of 10 measurements of either radium $\left({ }^{226} \mathrm{Ra}\right)$ reference source RRS100 or RRS500b. Results are analyzed as a ratio of the response of the ampoule to the response of the RRS. After correction for background, the resulting ratio is used to derive a calibration factor, or K-value, defined as the activity of a given radionuclide that would produce the same response as the RRS. The relative values of the RRS100 and RRS500b are well characterized. By determining the K-value using the activity derived from different ampoules of different activity levels, it is also possible to verify the gravimetric dilution factor. The dilution factor from $A 1$ to $A 1 D 1$ was verified by this method to within $0.022 \%$. The LTAC activity values and the mass dispensed into $A 1$ were used to determine $\mathrm{K}$-values that can be used for future measurements of ${ }^{68} \mathrm{Ge}$ in the NIST ampoule geometry.

\subsection{Gamma Ray Spectrometry}

The solution that remained in A1D2 after making the LS cocktails was analyzed for possible photon-emitting radionuclidic impurities using two calibrated HighPurity Germanium (HPGe) photon spectrometers at two different counting distances each. In addition, the data provided an additional, confirmatory measurement of the activity concentration using the $1078 \mathrm{keV}$ gamma ray from the decay of ${ }^{68} \mathrm{Ga}$. Characteristics of the detectors used in this study are given in Table 2.

Data were collected using the GammaVision-32 (Ortec, Oak Ridge, TN) software package and analyzed using both GammaVision-32 and Genie 2000 (Canberra, Meriden, CT). Detection efficiencies were calculated from efficiency-energy relationships determined using solutions previously calibrated at NIST and measured in the $5 \mathrm{~mL}$ NIST ampoule geometry. 


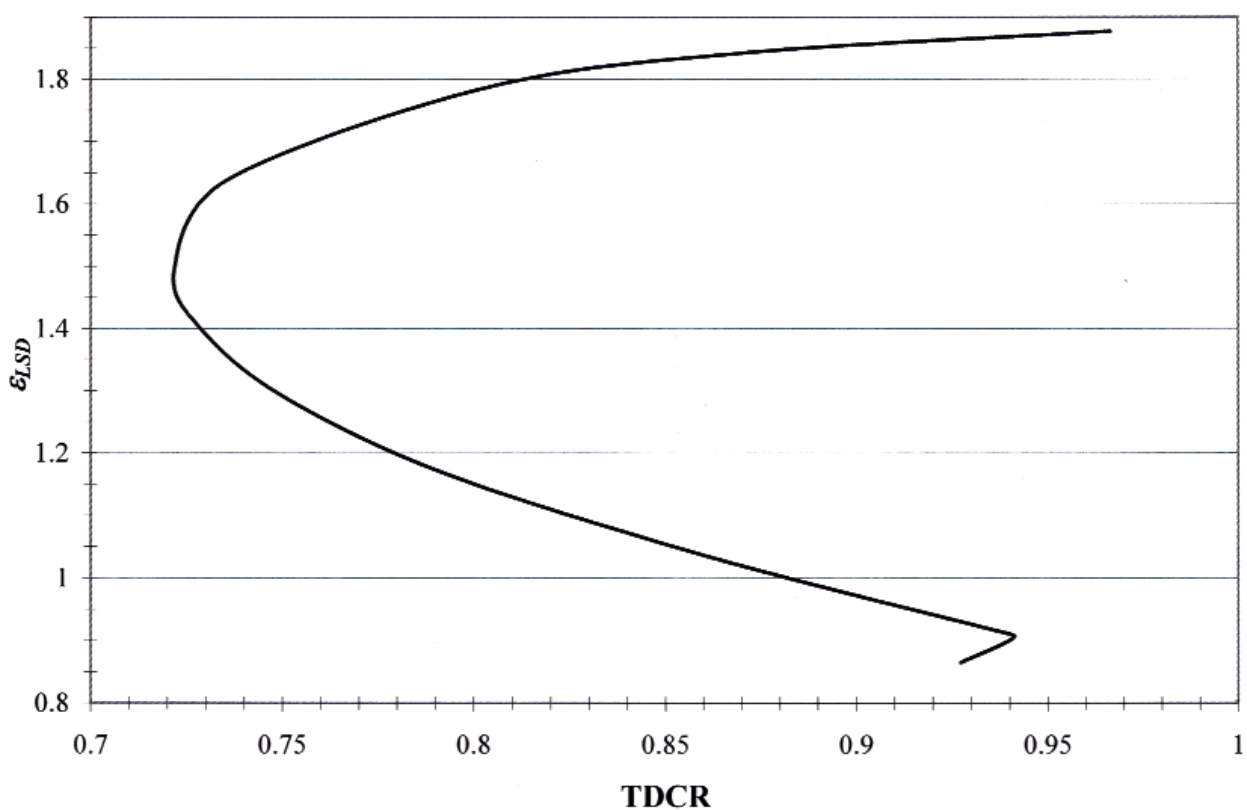

Fig. 5. Plot of theoretical efficiency of the logical sum of double coincidence events $\varepsilon_{\mathrm{LSD}}$ ) as a function of TDCR for ${ }^{68} \mathrm{Ge} /{ }^{68} \mathrm{Ga}$, assuming equal photomultiplier tube efficiencies and a $k B$ value of $0.012 \mathrm{~cm} \cdot \mathrm{MeV}^{-1}$

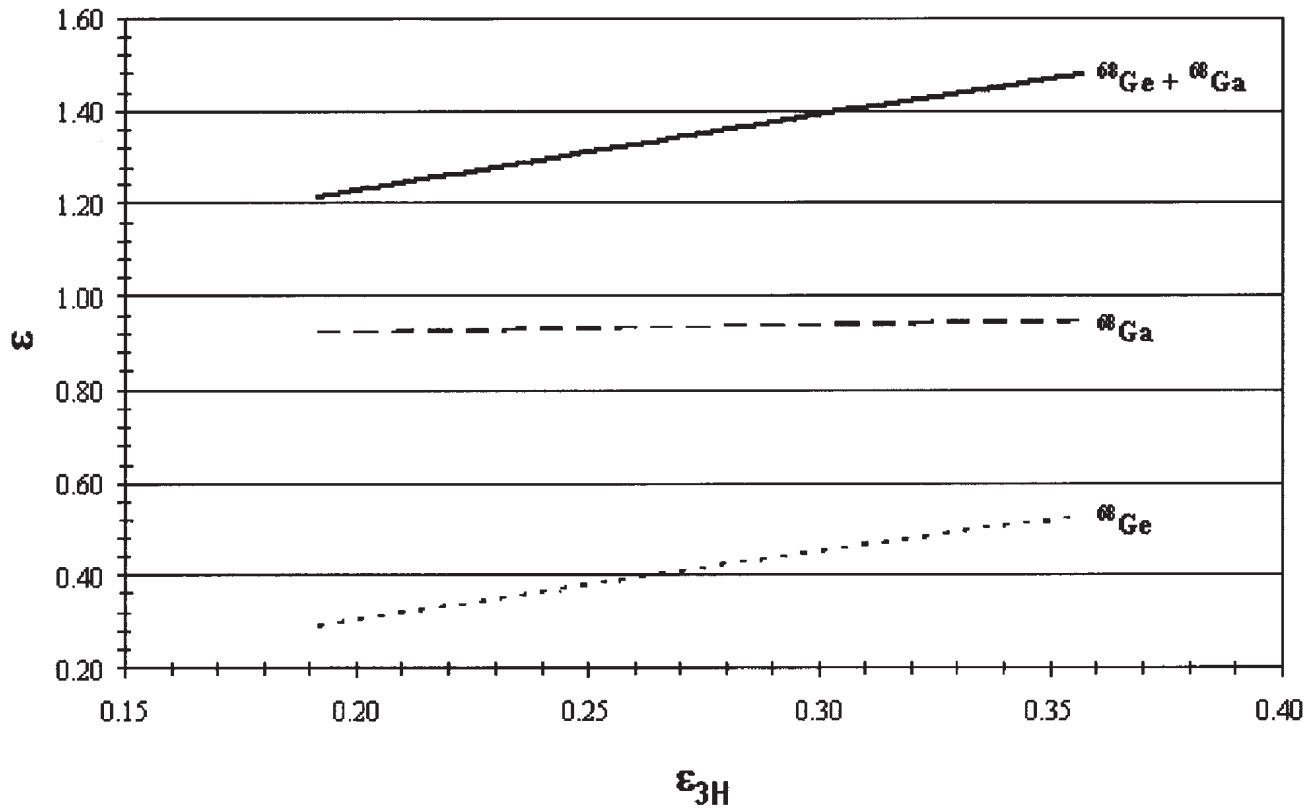

Fig. 6. Plot of theoretical ${ }^{68} \mathrm{Ge}$ (dotted line), ${ }^{68} \mathrm{Ga}$ (dashed line), and total (solid line) efficiencies as a function of tritium efficiency for Ultima Gold, assuming a $k B$ value of $0.0075 \mathrm{~cm} \cdot \mathrm{MeV}^{-1}$. 
Table 2. Characteristics of HPGe detectors used in the present study

\begin{tabular}{lll}
\hline \multicolumn{1}{c}{ Detector parameter } & X-detector & B-detector \\
\hline Detector diameter & $43.6 \pm 0.1 \mathrm{~mm}$ & $54.9 \pm 0.1 \mathrm{~mm}$ \\
Detector length & $36.2 \pm 0.1 \mathrm{~mm}$ & $54.2 \pm 0.05 \mathrm{~mm}$ \\
End cap window material & Beryllium & Beryllium \\
Window thickness & $0.5 \pm 0.05 \mathrm{~mm}$ & $0.5 \pm 0.05 \mathrm{~mm}$ \\
Crystal-window distance & $3 \pm 0.5 \mathrm{~mm}$ & $3 \pm 0.5 \mathrm{~mm}$ \\
Crystal top dead zone thickness & $0.3 \pm 0.03 \mu \mathrm{m}$ & $0.3 \pm 0.03 \mu \mathrm{m}$ \\
Crystal material & Germanium & Germanium \\
Crystal hole depth & $32.6 \pm 0.5 \mathrm{~mm}$ & $47.2 \pm 0.5 \mathrm{~mm}$ \\
Crystal hole diameter & $10.4 \pm 0.5 \mathrm{~mm}$ & $12 \pm 0.5 \mathrm{~mm}$ \\
Detector side cap thickness & $1.3 \pm 0.1 \mathrm{~mm}$ & $1.3 \pm 0.1 \mathrm{~mm}$ \\
Detector side cap diameter & $70 \pm 1 \mathrm{~mm}$ & $63.5 \pm 0.5 \mathrm{~mm}$ \\
Detector side cap material & Aluminum & Magnesium \\
Detector type & $n$-type & $n$-type \\
Calibration Geometries (distances are source-to-detector) & Ampoule; side-mount, end-on $24 \mathrm{~cm}$ & Ampoule; $24 \mathrm{~cm}, 35 \mathrm{~cm}$ \\
\hline
\end{tabular}

\section{Results and Discussion}

\subsection{Impurity Analyses}

No photon-emitting radionuclidic impurities were detected in solution $A 1$ to within the following limits (at the reference time) of the massic photon emission rate:

$$
\begin{aligned}
& 785 \mathrm{~s}^{-1} \cdot \mathrm{g}^{-1} \text { for } 30 \mathrm{keV} \leq E \leq 507 \mathrm{keV} ; \text { and } \\
& 285 \mathrm{~s}^{-1} \cdot \mathrm{g}^{-1} \text { for } 515 \mathrm{keV} \leq E \leq 1800 \mathrm{keV} ;
\end{aligned}
$$

where $E$ is the gamma-ray energy.

\subsection{Activity Measurements Results}

The results of the massic activity determinations for the solution contained in $A 1$ as of the reference time are given in Table 3 . The values in Table 3 take into account the dilution factor of 204.903231 between the solution in $A 1$ and that used in the assays, $A 1 D 2$. The uncertainties given in the table are expanded $(k=2)$ uncertainties based on the components given in Tables 4-7.

Of the different techniques used in this study to determine the activity concentration of the ${ }^{68} \mathrm{Ge}$ solution, the LTAC technique is much less dependent on level scheme data and model parameters not directly measured in the experiment. For this particular measurement, the only input parameter significantly impacting the activity calculation that was not directly measured in the experiment was the positron branching ratio. The other branching ratios only contributed to the
Table 3. Results of massic activity determinations $\left(\mathrm{C}_{\mathrm{A}}\right.$, in $\left.\mathrm{Bq} \cdot \mathrm{g}^{-1}\right)$ for the ${ }^{68} \mathrm{Ge}$ solution contained in ampoule $A 1$ as of the reference time of 12:00 EST 1 May 2007. The uncertainties, given in parentheses, are expanded $(k=2)$ uncertainties based on the evaluated uncertainty components listed in Tables 4-7 for the respective techniques

\begin{tabular}{lc}
\hline \hline Technique & $C_{\mathrm{A}}, 10^{6} \mathrm{~Bq} \cdot \mathrm{g}^{-1}$ \\
\hline $\begin{array}{l}4 \pi \beta-\gamma \text { anticoincidence counting } \\
\text { (LTAC) }\end{array}$ & $3.104(18)$ \\
LS counting with the Triple-to-Double & \\
Ratio (TDCR) method & $3.141(25)$ \\
LS counting with the CIEMAT/NIST & \\
${ }^{3} \mathrm{H}-$ standard efficiencytracing method \\
(CNET) \\
$\begin{array}{l}\text { Gamma-ray spectrophotometry with } \\
\text { High Purity Germanium } \\
\text { (HPGe) detectors }\end{array}$ \\
\hline
\end{tabular}

minor $(0.2 \%)$ correction for the leakage of $1077 \mathrm{keV}$ $\gamma$-rays into the annihilation $\gamma$-ray gate. And even this small correction was checked experimentally by modifying the experimental design to exaggerate the effect and then verifying that the corrected activity agreed with the original value.

On the other hand, our implementations of the TDCR and CNET efficiency tracing methods are unable to separate the positron and EC decay signals and must 
Table 4. Uncertainty components evaluated in the determination of the massic activity, $C_{\mathrm{A}}$, for ${ }^{68} \mathrm{Ge}$ solution $A 1$ by $4 \pi \beta-\gamma$ anticoincidence counting (LTAC)

\begin{tabular}{|c|c|c|c|}
\hline Component, $u_{i}$ & Comment & Evaluation type & $\%$ \\
\hline Measurement variability & $\begin{array}{l}\text { Standard deviation of the mean on the } \\
\text { determination of } C_{\mathrm{A}} \text { for } 8 \text { trials } \\
\text { encompassing } 4 \text { samples, } 3 \text { backgrounds, } \\
2 \text { extending dead-times and } \\
\text { absorber/no absorber- over a } \\
\text { 2-week period }\end{array}$ & A & 0.03 \\
\hline Background variability & $\begin{array}{l}\text { Additional variation estimate based } \\
\text { on } 3 \text { trials and within-run variation }\end{array}$ & A & 0.03 \\
\hline $\begin{array}{l}\text { Additional variability in } \\
\text { background }\end{array}$ & $\begin{array}{l}\text { Additional variability not embodied } \\
\text { by "random sources" }\end{array}$ & B & 0.05 \\
\hline Half-life & $\begin{array}{l}\text { Standard uncertainty in half-life . } \\
(0.059 \%) \text { over the measurement } \\
\text { decay interval }\end{array}$ & B & 0.0008 \\
\hline Livetime & $\begin{array}{l}\text { Estimated standard uncertainty on } C_{\mathrm{A}} \\
\text { due to uncertainty in counting livetime. }\end{array}$ & B & 0.1 \\
\hline Branching ratio & $\begin{array}{l}\text { Estimated standard uncertainty due to } \\
\text { uncertainty in published decay } \\
\text { branching ratios }\end{array}$ & B & 0.13 \\
\hline Extrapolation & $\begin{array}{l}\text { Estimated standard uncertainty due to } \\
\text { extrapolation to zero non-detection } \\
\text { efficiency; based on sensitivity tests, } \\
\text { previous measurements and models }\end{array}$ & B & 0.2 \\
\hline $\begin{array}{l}\text { Correction due to } \\
\text { detection of } 1077 \mathrm{keV} \\
\text { photons }\end{array}$ & $\begin{array}{l}\text { Estimated standard uncertainty on } C_{\mathrm{A}} \text { due } \\
\text { to efficiency of detecting } 1077 \mathrm{keV} \\
\text { photons based on sensitivity tests }\end{array}$ & B & 0.1 \\
\hline Mass determinations & $\begin{array}{l}\text { Estimated standard uncertainty of mass } \\
\text { for any single LS cocktail }\end{array}$ & B & 0.05 \\
\hline Dilution factor & $\begin{array}{l}\text { Uncertainty in } C_{\mathrm{A}} \text { of solution } \mathrm{Ge} 1 \mathrm{~A} 1 \text { due to } \\
\text { uncertainty in gravimetrically-determined } \\
\text { dilution factor between solutions in } \\
\text { ampoules Ge1A1 and Ge1A1D2 }\end{array}$ & B & 0.04 \\
\hline Combined $\left(u_{\mathrm{c}}=\sqrt{ } \sum u_{i}^{2}\right)$ & & & 0.29 \\
\hline Expanded $\left(U_{\mathrm{c}}=u_{\mathrm{c}} \cdot k ; k=2\right)$ & & & 0.58 \\
\hline
\end{tabular}


Table 5. Uncertainty components evaluated in the determination of the massic activity, $C_{\mathrm{A}}$, for ${ }^{68} \mathrm{Ge}$ solution $A 1$ by liquid scintillation counting using TDCR method

\begin{tabular}{|c|c|c|c|}
\hline Component, $u_{i}$ & Comment & Evaluation type & $\%$ \\
\hline Sample repeatability & $\begin{array}{l}\text { Standard deviation of the mean on the } \\
\text { determination of massic activity for a } \\
\text { single LS cocktail }(n=3-5 \\
\left.\text { determinations of } C_{\mathrm{A}} \text { per source }\right)\end{array}$ & A & 0.06 \\
\hline $\begin{array}{l}\text { LS cocktail composition } \\
\text { variability }\end{array}$ & $\begin{array}{l}\text { Standard deviation on the determination } \\
\text { of } C_{\mathrm{A}} \text { for three } \mathrm{LS} \text { cocktail compositions } \\
\text { ( } n=6-19 \text { determinations of } C_{\mathrm{A}} \\
\text { per composition) }\end{array}$ & A & 0.09 \\
\hline Efficiency dependence & $\begin{array}{l}\text { Median difference between maximum and } \\
\text { minimum value of } C_{\mathrm{A}} \text { determined for a single } \\
\text { source at between } 3 \text { and } 4 \text { efficiency values, } \\
\text { varied by use of grey filters ( } n=12 \\
\text { independent measurements) }\end{array}$ & B & 0.20 \\
\hline $\begin{array}{l}\text { Effect of }{ }^{68} \mathrm{Ga} \text { beta } \\
\text { endpoint energy, } \mathrm{E}_{\beta, \max } \text { on } \\
\text { efficiency calculations }\end{array}$ & $\begin{array}{l}\text { Standard uncertainty in efficiency } \\
\text { calculation due to standard uncertainties } \\
\text { on positron endpoint energies of }{ }^{68} \mathrm{Ga}\end{array}$ & B & 0.18 \\
\hline $\begin{array}{l}\text { Effect of other atomic and } \\
\text { nuclear input data }\end{array}$ & $\begin{array}{l}\text { Standard uncertainty due to uncertainties on data } \\
\text { used as input to the TDCR analysis code as } \\
\text { determined by Monte Carlo methods. A total of } 20 \\
\text { data sets were generated from normal distributions } \\
\text { defined by the published nuclear and atomic data } \\
\text { and their associated standard uncertainties, which } \\
\text { were taken as the standard deviation of the respective } \\
\text { distributions. Each data set was used to calculate } C_{\mathrm{A}} \\
\text { using a single experimental data set }\end{array}$ & A & 0.26 \\
\hline Half-life & $\begin{array}{l}\text { Standard uncertainty in half-life }(0.059 \%) \\
\text { over the measurement decay interval }\end{array}$ & B & $6 \cdot 10-3$ \\
\hline Mass determinations & $\begin{array}{l}\text { Estimated standard uncertainty of mass } \\
\text { for any single LS cocktail }\end{array}$ & B & 0.05 \\
\hline Livetime & $\begin{array}{l}\text { Standard uncertainty arising from an } \\
\text { estimated uncertainty of } 0.007 \% \\
\text { on the determination of the live time }\end{array}$ & B & $7 \cdot 10^{-3}$ \\
\hline Background & $\begin{array}{l}\text { Standard deviation on the determination of } C_{\mathrm{A}} \\
\text { determined via Monte Carlo simulation. A total of } \\
5 \text { background data sets were constructed from random } \\
\text { data arising from normal distributions defined by } \\
\text { the average and standard deviation of experimental } \\
\text { backgrounds at } 4 \text { efficiency points having } 3 \text { repetitions } \\
\text { each; calculations were carried out with all } 5 \text { background } \\
\text { data sets for a single experimental data set }\end{array}$ & A & $5 \cdot 10^{-3}$ \\
\hline Dilution factor & $\begin{array}{l}\text { Uncertainty in } C_{\mathrm{A}} \text { of solution Ge1A1 due to uncertainty } \\
\text { in gravimetrically-determined dilution factor between } \\
\text { solutions in ampoules Ge1A1 and Ge1A1D2 }\end{array}$ & B & 0.04 \\
\hline Combined $\left(u_{\mathrm{c}}=\sqrt{ } \sum u_{i}^{2}\right)$ & & & 0.39 \\
\hline Expanded $\left(U_{\mathrm{c}}=u_{\mathrm{c}} \cdot k ; k=2\right)$ & & & 0.79 \\
\hline
\end{tabular}




\section{Journal of Research of the National Institute of Standards and Technology}

Table 6. Uncertainty components evaluated in the determination of the massic activity, $C_{\mathrm{A}}$, for ${ }^{68} \mathrm{Ge}$ solution $A 1$ by liquid scintillation counting using CIEMAT/NIST ${ }^{3} \mathrm{H}$ standard efficiency tracing method

\begin{tabular}{|c|c|c|c|}
\hline Component, $u_{i}$ & Comment & Evaluation type & $\%$ \\
\hline Sample repeatability & $\begin{array}{l}\text { Standard deviation of the mean on the } \\
\text { determination of massic activity for a single LS } \\
\text { cocktail ( } n=10 \text { determinations of } C_{\mathrm{A}} \text { per source) }\end{array}$ & A & 0.05 \\
\hline $\begin{array}{l}\text { LS measurement } \\
\text { reproducibility }\end{array}$ & $\begin{array}{l}\text { Standard deviation on the determination of } C_{\mathrm{A}} \text { for } \\
10 \text { cocktails of } 2 \text { compositions }\end{array}$ & A & 0.24 \\
\hline Mass determinations & $\begin{array}{l}\text { Estimated standard uncertainty of }{ }^{68} \mathrm{Ge} \text { mass for } \\
\text { any single LS cocktail }\end{array}$ & B & 0.05 \\
\hline Dilution factor & $\begin{array}{l}\text { Uncertainty in } C_{\mathrm{A}} \text { of solution Ge1A1 due to } \\
\text { uncertainty in gravimetrically-determined } \\
\text { dilution factor between solutions in ampoules } \\
\text { Ge1A1 and Ge1A1D2 }\end{array}$ & B & 0.04 \\
\hline${ }^{68} \mathrm{Ge}$ decay corrections & $\begin{array}{l}\text { Standard uncertainty in half-life }(0.059 \%) \\
\text { over the measurement decay interval }\end{array}$ & B & 0.001 \\
\hline${ }^{68} \mathrm{Ge}$ efficiency & $\begin{array}{l}\text { Estimated uncertainty in } C_{\mathrm{A}} \text { due to step size } \\
\text { in } \mathrm{CN} 2004 \text { calculations }\end{array}$ & B & 0.65 \\
\hline Livetime determinations & $\begin{array}{l}\text { Estimated uncertainty in the correction to the } \\
\text { LS counting interval }\end{array}$ & B & $\begin{array}{c}0.05 \\
(\text { and } \mathrm{PE})^{3}\end{array}$ \\
\hline Background & $\begin{array}{l}\text { Estimated uncertainty due to an average } 4 \% \\
\text { uncertainty in background determination }\end{array}$ & B & 0.004 \\
\hline Activity of ${ }^{3} \mathrm{H}$ standard & $\begin{array}{l}\text { Estimated uncertainty due to } 0.36 \% \text { uncertainty } \\
\text { in }{ }^{3} \mathrm{H} \text { standard activity }\end{array}$ & B & 0.18 \\
\hline Branching ratios & $\begin{array}{l}\text { Estimated uncertainty due to uncertainty in } \\
\text { branching ratios }\end{array}$ & B & 0.08 \\
\hline Combined $\left(u_{\mathrm{c}}=\sqrt{ } \sum u_{i}^{2}\right)$ & & & 0.73 \\
\hline Expanded $\left(U_{\mathrm{c}}=u_{\mathrm{c}} \cdot k ; k=2\right)$ & & & 1.45 \\
\hline
\end{tabular}


Table 7. Uncertainty components evaluated in the determination of the massic activity, $C_{\mathrm{A}}$, for ${ }^{68} \mathrm{Ge}$ solution Ge1A1 by $\gamma$-ray spectrometry using HPGe detectors

\begin{tabular}{|c|c|c|c|}
\hline Component, $u_{i}$ & Comment & Evaluation type & $\%$ \\
\hline Measurement repeatability & $\begin{array}{l}\text { Standard deviation on determination of } C_{\mathrm{A}} \\
\text { for } 3 \text { repeated measurements of a single } \\
\text { source at a single geometry }\end{array}$ & $\mathrm{A}$ & 0.98 \\
\hline Efficiency curve & $\begin{array}{l}\text { Standard deviation of the mean on determination } \\
\text { of detection efficiency for } 4 \text { sample geometries }\end{array}$ & B & 0.12 \\
\hline Sample geometry & $\begin{array}{l}\text { Typical uncertainty due to change of sample } \\
\text { geometry (detector and source-to-detector distance) } \\
\text { for a single counting source }\end{array}$ & B & 0.33 \\
\hline Decay correction & $\begin{array}{l}\text { Standard uncertainty in half-life }(0.059 \%) \text { over } \\
\text { the measurement decay interval }\end{array}$ & B & $2.6 \cdot 10^{-3}$ \\
\hline Decay data & $\begin{array}{l}\text { Standard uncertainty }(0.93 \%) \text { on emission } \\
\text { probablity of } 1078 \mathrm{keV} \text { gamma-ray in the } \\
\text { decay of }{ }^{68} \mathrm{Ge}\end{array}$ & B & 0.93 \\
\hline Dilution factor & $\begin{array}{l}\text { Estimated standard uncertainty in } C_{\mathrm{A}} \text { of } \\
\text { solution Ge1A1 due to uncertainty in } \\
\text { gravimetrically-determined dilution factor } \\
\text { between solutions in ampoules Ge1A1 } \\
\text { and Ge1A1D2 }\end{array}$ & B & 0.04 \\
\hline Combined $\left(u_{\mathrm{c}}=\sqrt{ } \sum u_{i}^{2}\right)$ & & & 1.4 \\
\hline Expanded $\left(U_{\mathrm{c}}=u_{\mathrm{c}} \cdot k ; k=2\right)$ & & & 2.8 \\
\hline
\end{tabular}

therefore account for all possible decay paths, including atomic rearrangements following electron capture. From a practical standpoint, a compromise between treating all possible paths and reasonable computation times must be made. While this certainly introduces some small amount of uncertainty, it is not expected that the weak contributions due to paths not considered in Fig. 4 would be significant, at least for the TDCR method. Instead, as seen in Table 5, the uncertainties on the input data play a very significant role.

Because of the more direct nature of the measurement in the LTAC technique, the LTAC activity value for the solution in $A 1$ was adopted as the reference value for this study and was used in the calculation of the K-value for the NIST IC. The fact that the LTAC and TDCR measurements agree to within their respective experimental uncertainties is encouraging, given the complexity of the TDCR efficiency calculation. Nonetheless, one would hope that improvements in the NIST TDCR spectrometer would lead to higher EC detection efficiencies, thereby providing better results in the measurement of radionuclides that decay by this mode. The CNET results indicate that some improvements in the method are still needed to be able to reliably measure nuclides that undergo EC decay.

\subsection{Determination of K-Value for NIST IC}

In order to avoid the need to perform a primary standardization every time a NIST-calibrated solution of ${ }^{68} \mathrm{Ge} /{ }^{68} \mathrm{Ga}$ is required, we determined a calibration factor (K-value) for the NIST IC. This K-value is not to be confused with the coverage factor, $k$, applied to uncertainty evaluations. Using the LTAC reference activity value and the measured responses in the IC against radium reference sources (RR) $500 \mathrm{~B}$ and 100 , the $\mathrm{K}$-values were found to be $2.695 \times 10^{7} \pm 1.7 \times 10^{5} \mathrm{~Bq}$ and $5.032 \times 10^{6} \pm 3.2 \times 10^{4} \mathrm{~Bq}$, respectively. The uncertainties on the K-values are expanded $(k=2)$ uncertainty and include relative standard uncertainty components due to the original primary standardization $(0.29 \%)$, 
repeatability on 40 measurements in the IC $(0.015 \%)$, source mass $(0.05 \%)$, decay correction $(0.002 \%)$, and source positioning $(0.1 \%)$.

\section{Conclusion}

A solution containing ${ }^{68} \mathrm{Ge}$ in equilibrium with its decay daughter ${ }^{68} \mathrm{Ga}$ has been standardized for the first time at NIST, with a combined standard uncertainty of $0.29 \%$ using LTAC. Measurements made with two other LS techniques, TDCR and CNET, confirmed the LTAC result to within $1.1 \%$ and $1.5 \%$, respectively. The differences between results obtained with the latter two methods and the LTAC technique indicate that improvements in the models and/or their applications are needed, particularly for EC nuclides.

Data collected on the NIST $4 \pi \gamma$ ionization chamber allowed for the determination of calibration factors for that chamber in the $5 \mathrm{~mL}$ NIST ampoule geometry, thereby enabling future calibrations of solutions having the same solution composition without the need for the measurements to be made by a primary method.

\section{Acknowledgments}

The authors wish to thank Ms. Michelle Hammond and Dr. Leticia Pibida for performing the HPGe measurements.

A portion of this work was supported by RadQual, LLC.

\section{References}

[1] G. Wiley, PET/CT: Market \& Business Models for Ownership, Imaging Economics 6 (2006).

[2] B. M. Coursey, D. D. Hoppes, M. P. Unterweger, A. Grau Malonda, R. A. Margolin, R. M. Kesslerr, and R. Manning, Standardization of ${ }^{18} \mathrm{~F}$ for use in Positron-Emission Tomography, Int. J. Appl. Radiat. Isot. 34, 1181-1189 (1983).

[3] B. E. Zimmerman, G .J. Kubicek, J. T. Cessna, P. S. Plascjak, and W. C. Eckelman, Radioassays and experimental evaluation of dose calibrator settings for ${ }^{18} \mathrm{FDG}$, Appl. Radiat. Isot. 54, 113-122 (2001).

[4] DDEP, Decay Data Evaluation Project Data, http://www. nucleide.org/DDEP_WG/DDEPdata.htm (2008).

[5] E. Schönfeld, U. Schötzig, E. Günther, and H. Schrader, Standardization and decay data of ${ }^{68} \mathrm{Ge} /{ }^{68} \mathrm{Ga}$, Appl. Radiat. Isot. 45, 955-961 (1994).
[6] B. M. Coursey, W. B. Mann, A. Grau Malonda, E. GarcìToraño, J. M. Los Arcos, J. A. B. Gibson, and D. Reher, Standardization of carbon-14 by $4 \pi \beta$ liquid scintillation efficiency tracing with hydrogen-3, Appl. Radiat. Isot. 5, 403408 (1986).

[7] B. E. Zimmerman and R. Collé, Standardization of ${ }^{63} \mathrm{Ni}$ by $4 \pi \beta$ liquid scintillation spectrometry with ${ }^{3} \mathrm{H}$-standard efficiency tracing, J. Res. Natl. Inst. Stand. Technol. 102, 455-477 (1997).

[8] E. L. Grigorescu, C. D. Negut, A. Luca, A. C. Razdolescu, and M. Tanase, Standardization of ${ }^{68}(\mathrm{Ge}+\mathrm{Ga})$, Appl. Radiat. Isot. 60, 429-432 (2004).

[9] R. Broda and K. Pochwalski, The enhanced triple to double coincidence ratio (ETDCR) method for standardization of radionuclides by liquid scintillation counting, Nucl. Inst. Meth. Phys. Res. A312, 85-89 (1992).

[10] K. Pochwalski, R. Broda, and T. Radoszewski, Standardization of pure beta emitters by liquid scintillation counting, Appl. Radiat. Isot. 39, 165-172 (1988).

[11] International Organization for Standardization (ISO), Guide to the Expression of Uncertainty in Measurement (ISO, Geneva, 1993).

[12] B. N. Taylor and C. E. Kuyatt, Guidelines for evaluating and expressing the uncertainty of NIST measurement results, NIST Technical Note 1297 (National Institute of Standards and Technology, Gaithersburg, MD, 1994).

[13] J. M. Calhoun, NBS Special Publication 250-10: Radioactivity calibrations with the ' $4 \pi$ ' gamma ionization chamber and other radioactivity calibration capabilities, NBS Special Publication 250-10 (National Institute of Standards and Technology, Gaithersburg, MD, 1987).

[14] National Institute of Standards and Technology, Standard Reference Material 4927F, Radioactivity Standard, Hydrogen-3, (National Institute of Standards and Technology, Gaithersburg, MD, 2000).

[15] R. Fitzgerald and M. K. Schultz, Liquid scintillation-based anticoincidence counting of Co-60 and Pb-210, Appl. Radiat. Isot. 66, 937-940 (2008).

[16] L. L. Lucas, Calibration of the massic activity of a solution of Tc-99, Appl. Radit Isot. 49, 1061-1064 (1998).

[17] B. E. Zimmerman, R. Collé, and J. T. Cessna, Construction and implementation of the NIST triple-to-double coincidence ratio (TDCR) spectrometer, Appl. Radiat. Isot. 60, 433-438 (2004).

[18] Wolfram Research, Mathematica, v.4.0, (2001).

[19] R. Broda, A review of the triple-to-double coincidence ratio (TDCR) method for standardizing radionuclides, Appl. Radiat. Isot. 58, 585-594 (2003).

[20] P. Cassette, M. M. Bé, F. Jaubert, and M. C. Lépy, Measurement of a ${ }^{103} \mathrm{Pd}$ solution using the TDCR method by LSC, Appl. Radiat. Isot. 60, 439-446 (2004).

[21] P. Cassette, SPEBETA programme de calcul du spectre en énergie des électrons émis par des radionucléides émetteurs beta, CEA Technical Note (Commissariat à l'Énergie Atomique (CEA), Saclay, France (1992).

[22] J. Sempau, E. Acosta, J. M. Fernandez-Varea, and F. Salvat, An algorithm for Monte Carlo simulation of the coupled electronphoton transport., Nucl. Inst. Meth. B132, 377-390 (1997). 
[23] B. E. Zimmerman, Monte Carlo calculations of spectra and interaction probabilities for photons in liquid scintillators for use in the standardization of radionuclides, Appl. Radiat. Isot. 64, 1492-1498 (2006).

[24] National Institute of Standards and Technology, Electron Stopping Power and Range Tables, http://physics.nist.gov/STAR (2008).

[25] Labortoire National Henri Becquerel, LS Sources Data, http://www.nucleide.org/ICRM_LSC_WG/icrmlsdata.htm (2008).

[26] R. Collé, B. E. Zimmerman, P. Cassette, and L. LaureanoPerez, ${ }^{63} \mathrm{Ni}$, its half-life and standardization: revisited, Appl. Radiat. Isot. 66, 60-68 (2008).

[27] E. Günther, CIENIST 2004, private communication (2004).

About the authors: Dr. B. E. Zimmerman is a research chemist in the Radioactivity Group (Ionizing Radiation Division) of the NIST Physics Laboratory. Mr. J. T. Cessna and Dr. R. Fitzgerald are physicists in NIST Radioactivity Group. The National Institute of Standards and Technology is an agency of the U.S. Department of Commerce. 